\title{
List of Contributors
}

Anna Alberini, Department of Agricultural and Resource Economics, University of Maryland, USA and Fondazione Eni Enrico Mattei, Italy.

Margaretha Breil, Fondazione Eni Enrico Mattei, Italy.

Arianne de Blaeij, Department of Spatial Economics, Free University, Amsterdam, The Netherlands.

Edi Defrancesco, Department of Land and Agro-Forestry Systems, University of Padua, Italy.

Anita Fassio, Fondazione Eni Enrico Mattei, Italy.

Carlo Giupponi, Department of Crop Science, University of Milan, Italy and Fondazione Eni Enrico Mattei, Italy.

Alberto Longo, Department of Economics and International Development, University of Bath, UK.

Paulo A.L.D. Nunes, Department of Economics, Ca' Foscari University, Venice, Italy, Fondazione Eni Enrico Mattei, Italy and Department of Spatial Economics, Free University, The Netherlands.

Paolo Rosato, Department of Civil Engineering, University of Trieste and Fondazione Eni Enrico Mattei, Italy.

Luca Rossetto, Department of Land and Agro-Forestry Systems, University of Padua, Italy.

Stefania Tonin, Department of Planning, University IUAV, Italy.

Francesco Trombetta, Eni and Department of Planning, University IUAV, Italy.

Margherita Turvani, Department of Planning, University IUAV and School for Advanced Studies in Venice Foundation, Italy.

Valentina Zanatta, DICAS, Polytechnic of Turin and Fondazione Eni Enrico Mattei, Italy. 